\title{
Role of Bronchial Brush Cytology in Diagnosis of Central Bronchial Carcinoma
}

\author{
B SULTANA $^{\mathrm{a}}$, MI PATWARY ${ }^{\mathrm{b}}$, M RAHMAN $^{\mathrm{c}}$, \\ SAHMM ISLAM $^{\mathrm{d}}$, D HOSSAIN ${ }^{\mathrm{e}}$
}

\begin{abstract}
Summary:
Background: Despite the advances in imaging techniques and treatment modalities, the prognosis of lung cancer remains poor, with five-year survival of $14 \%$ at early stages and less than $5 \%$ in locally advanced stages. Before starting treatment a clear distinction between small cell and nonsmall cell carcinoma must be made, for that histopathology remains the mainstay of confirmation of diagnosis. To combat the disease successfully, it should be diagnosed at earliest possible stage. If bronchial brush cytology yield comparable diagnostic specificity, then it may easy for the patient and physician to manage this fatal disease.
\end{abstract}

Purpose: The study was designed to evaluate the diagnostic yield of bronchial brush cytology in central (endoscopically visible) bronchial carcinoma

Subjects and methods: This cross sectional study was done in the Department of Medicine, and Respiratory Medicine units of Sylhet MAG Osmani Medical College Hospital, Sylhet during the period from July 2012 to June 2014.Thirty seven patients with clinically suspected bronchial carcinoma

Introduction:

Lung cancer is the most common cause of death from cancer worldwide, causing 1.4 million deaths per year. ${ }^{1}$ It is the leading cause of cancer deaths in developed countries and is also rising at alarming rates in developing countries. ${ }^{2}$, In Bangladesh, the occurrence

a. Dr. Bilkis Sultana, Sylhet M.A.G. Osmani Medical College, Sylhet.

b. Prof. Md. Ismail Patwary, Professor and Head, Department of Medicine, Sylhet M.A.G.Osmani Medical College, Sylhet.

c. Prof. Matiur Rahman, Professor. Department of neurology, Sylhet M.A.G.Osmani Medical College, Sylhet

d. Dr. SAHM Meshbahul Islam, Assistant Professor, Department of Respiratory Medicine, Sylhet M.A.G.Osmani Medical College, Sylhet

e. Dr. Delwar Hossain Assistant Professor, Department of Respiratory Medicine, Sylhet M.A.G.Osmani Medical College, Sylhet

Address of Correspondence: Prof. Md. Matiur Rahman, email:ma5ti@yahoo.com

Received: 20 July 2016

Accepted: 3 February 2017 were enrolled in this study fulfilling the inclusion and exclusion criteria. In all cases bronchial brush cytology and endo-bronchial biopsy were performed and results of both techniques were compared

Reasults: The mean age of the patients with bronchial carcinoma was 59.65 (SD 12.95) years; 28 (75.7\%) patients were 51 years or above with a ratio of male to female of 17.5:1. The sensitivity of bronchial brush cytology in the diagnosis of central bronchial carcinoma was $89.2 \%$ and that of endobronchial biopsy was $67.6 \%$, no true negative cases were detected. Five (13.5\%) patients developed respiratory distress and minor bleeding in 4 (10.8\%) as a complications of bronchoscopy procedure.

Conclusion: The diagnostic yield of bronchial brush cytology is non inferior to than that of endobronchial biopsy in the diagnosis of central bronchial carcinoma.

key words: Bronchial brush cytology, Endobronchial biopsy, Central bronchial carcinoma.

(J Bangladesh Coll Phys Surg 2017; 35: 68-74)

of lung cancer is $16.7 \%$ of all cancers and the most common cancer $(25 \%)$ among the male cancer patients with 6.1:1 male female ratio. ${ }^{3}$ The incidence of bronchial cancer is increased due to increase in smoking habit, change in life styles, increased environmental pollution and the availability of different modern diagnostic modalities to detect lung cancer. Fifteen percent of lifetime smokers develop lung cancer, but $10 \%$ of lung cancers occur in non-smokers. ${ }^{4}$ Bronchial carcinoma has one of the lowest survival outcomes of any cancer because over two-thirds of patients are diagnosed at a late stage when curative treatment is not possible. Despite the advances in imaging techniques and treatment modalities, the prognosis of lung cancer remains poor, with five-year survival of $14 \%$ at early stages and less than $5 \%$ in locally advanced stages. Before starting treatment a clear distinction between small cell and non-small cell carcinoma must be made, for that histopathology remains the mainstay of confirmation of diagnosis. ${ }^{3-5}$ To combat the disease successfully, it should be diagnosed at earliest possible 
stage. For early diagnosis different diagnostic modalities are available which include; radiology, bronchoscopy, bronchial biopsy, exfoliative cytology, brushing, washing and fine needle aspiration cytology. It is not possible to perform all techniques in each patient because each has specific advantages and disadvantages. ${ }^{6}$ Flexible bronchoscopy plays a central role in the diagnosis of lung malignancy and intrathoracic staging, especially in endoscopically visible tumours. ${ }^{7}$,

${ }^{8}$ Bronchoscopy allows the sampling of cytological specimens as well as biopsies for histological diagnosis. Bronchoscopic cytological methods include bronchial washings, bronchial brushings, bronchoalveolar lavage, and transbronchial and endobronchial needle aspirations. ${ }^{9}$ Different methods have potentially important differences in the diagnostic sensitivity; ${ }^{10,11}$ and each of these modalities has an average yield of 50 to $85 \%$. When an endobronchial tumour is visible at bronchoscopy, forceps biopsies are the most common specimen collected and usually have the highest diagnostic yield. ${ }^{9}$ However bronchial brushing is easily performed and well tolerated procedure than endobrochial biopsy without hazard of bleeding and pneumothorax. ${ }^{12}$ The most important is that the brush is stroked back and forth over a considerable (1 to $2 \mathrm{~cm}$ ) surface of the tumour, increasing the likelihood of obtaining some cells with malignant characteristics on the bristles of the brush. On the other hand the biopsy forceps has a cup diameter only slightly greater than $1 \mathrm{~mm}$; the specimens obtained with the biopsy forceps are small and come from only one area of what appears to be tumour. ${ }^{13,14}$ In detecting lung malignancy sensitivity of bronchial brushing varies between 48$85.1 \%$ in different studies. ${ }^{9,10,15-19}$ Some studies showed that endobronchial biopsy was superior to bronchial brush cytology in the diagnosis of bronchial carcinoma; 20,21 while other showed bronchial brush cytology is superior to endobronchial biopsy in the diagnosis of bronchial carcinoma. ${ }^{13,14}$ So, this study was designed to evaluate the diagnostic yield of bronchial brush cytology in central lesion of bronchial cancer.

\section{Methodology:}

A cross-sectional comparative study was conducted in the Department of Medicine and Respiratory medicine in collaboration with the Department of Pathology, Sylhet M.A.G. Osmani Medical College Hospital, Sylhet. from $1^{\text {st }}$ July 2012 to $30^{\text {th }}$ June 2014.
Study Population: All patients with clinically and radiologically suspected central bronchial cancer, admitted in the different unit of Medicine, Sylhet M.A.G. Osmani Medical College Hospital, Sylhet were the target population and those who fulfilled the inclusion and exclusion criteria were enrolled as the study sample

\section{Inclusion Criteria}

- Radiological lesion (Chest X-ray) suggestive of centrally placed malignancy,

o prominence of a hilar shadow with whiskering appearance.

o hilar/parahilar masses,

o mediastinal widening,

o complete or partial collapse of lung.

- Central bronchial cancer on endoscopic findings visible by fibreoptic bronchoscopy

- Age more than 18 years

- Both sex

\section{Exclusion Criteria}

- All bronchial carcinoma approaching carina.

- All peripheral lung lesion

- Significantly disabled patients due to poor general condition.

- Patient who refused to enroll in this study

\section{Sample Size Calculation}

Considering the prevalence of lung cancer of $2.1 \%,{ }^{22}$ with 5\% significance level and 5\% marginal error sample size was calculated by using the Guilford and Frucher formula. Calculated sample size was 32 . But in this study we took all cases during the study periods of two years satisfying the inclusion and exclusion criteria and it was 37.

Sampling technique: Consecutive convenient (purposive) sampling.

Data Collection: Data were collected in a pre-designed data collection sheet designed for the study.

\section{Procedure of data collection}

Informed written consent was obtained from the patients or attendants after full explanation of the details of the disease process. 
After admission, a rapid diagnostic work up was made by clinical history, through physical examinations and necessary investigations. Demographic information like age, sex, occupation, socio-economic status, smoking status, etc. were obtained. All patients were investigated for Blood for CBC and ESR, X-ray chest P/A and Lateral view, Sputum for AFB, Bleeding time and Clotting time ECG and Bronchoscopy. Fiberoptic bronchoscopy was performed transnasally with the Olympus BF 1T-30 flexible bronchoscope (Olympus, Tokyo, Japan) in the Department of Medicine, Sylhet M.A.G. Osmani Medical College Hospital, Sylhet.

When an endobronchial lesion was suspected, the brush was inserted through fibreoptic bronchoscope channel and was moved to and fro over the endobronchial lesion, entrapping the bits of tissues and cells between the bristles. After the removal from the bronchoscope, the brush was advanced to make smear directly on the clean glass slides (6-8), which were immediately immersed in a koplic jar filled with 95\% alcohol. The jar was sent to the laboratory. After brushing, biopsy forcep was passed through the bronchoscope's channel in the closed position. Once satisfactory placement in the suspected area of involvement was achieved, the forcep was retracted 1 to $2 \mathrm{~cm}$ and then it was opened and advanced into the lesion. The forcep was gently closed and slowly retracted while the bronchoscope was secured in same position. The biopsy forcep along with the specimen was withdrawn from the bronchoscope. Multiple specimens (3-5) were taken from the suspected area of the lesion. The biopsy specimens were placed in $10 \%$ formalin solution and sent to the Sylhet MAG Osmani Medical College laboratory for histopathology.

Biopsy or cytological specimens that showed atypical or suspicious cells were regarded as non-diagnostic. Cytological analysis was considered positive only when large numbers of definitely malignant cells were present. In all 37 cases diagnosis of bronchial carcinoma was made by brush cytology, endobronchial biopsy or by both techniques along with strong clinical background.

Out of 12 endobronchial biospy negative but bronchial brush cytology positive for malignancy cases, 4 cases were evaluated by FNAC and was positive for malignancy. The remaining 8 cases had strong clinical background with radiological evidence of malignancy.

\section{Data analysis}

All the collected data were compiled and analyzed both manually and using the SPSS (Statistical package for social science) 17 for windows.

Quantitative data were expressed as mean and standard deviation.

Qualitative data were expressed as frequency, percentage, proportion and ratio; and comparison were carried by Chi-square $\left(C^{2}\right)$ test and $\mathrm{Z}$ test for proportion. A P value of $<0.05(\mathrm{p}<0.05)$ was considered statistically significant and a $\mathrm{P}$ value of $>0.05(\mathrm{p}>0.05)$ was considered statistically not significant.

\section{Results:}

Distribution of the age of the patients with bronchial carcinoma:

The age of the patients with bronchial carcinoma ranged from 34 to 90 years with the mean age of $59.65 \pm 12.95$ years as shown in figure1.

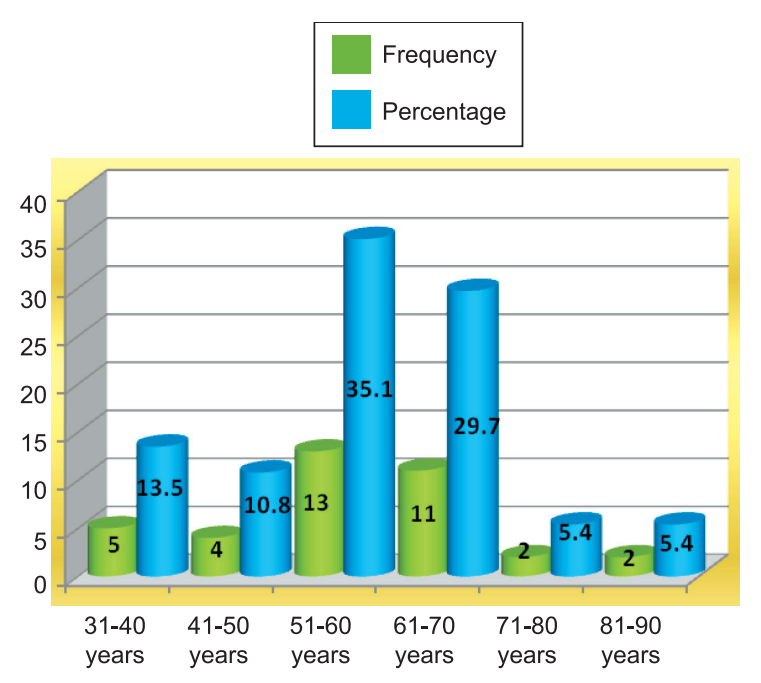

Fig.-1: Distribution of the age of the patients with bronchial carcinoma $(n=37)$.

\section{Distribution of respondents according to sex:}

In this study 35 (94.6\%) patients were male and 2 (5.4\%) patients were female with a ratio of male to female of 17.5:1. 


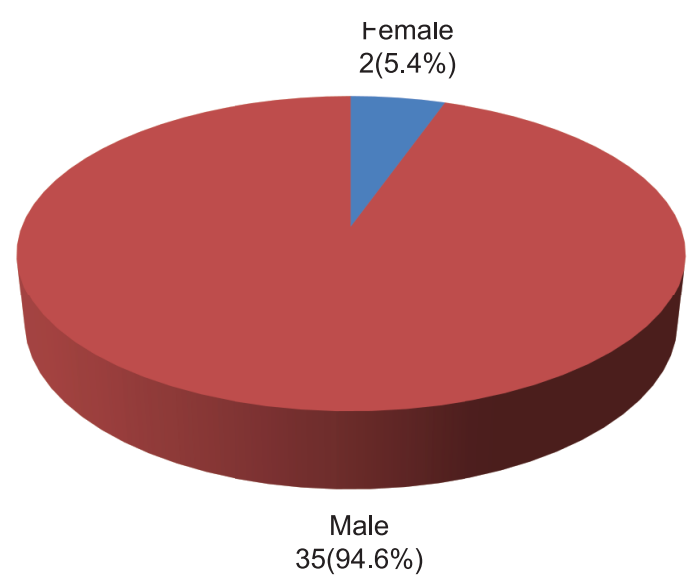

Fig.-2: Distribution of respondents according to sex.

\section{Table-I}

Findings of bronchial brush cytology in 37 cases of bronchial carcinoma $(n=37)$

\begin{tabular}{lcc}
$\begin{array}{l}\text { Bronchial brush } \\
\text { cytology results }\end{array}$ & Frequency & Percentage \\
\hline Squamous cell carcinoma & 25 & 67.6 \\
Adenocarcinoma & 4 & 10.8 \\
Small cell carcinoma & 4 & 10.8 \\
Non-conclusive & 4 & 10.8 \\
\hline Total & 37 & 100.0 \\
\hline
\end{tabular}

Endobronchial biopsy and histopathology revealed bronchial carcinoma in $25(67.6 \%)$ patients and 12 (32.4\%) had no malignancy detected

\section{Table-II}

Findings of endobronchial biopsy in 37 cases of bronchial carcinoma $(n=37)$

\begin{tabular}{lcc} 
Histopathology results & Frequency & Percentage \\
\hline Squamous cell carcinoma & 18 & 48.6 \\
Adenocarcinoma & 4 & 10.8 \\
Small cell carcinoma & 3 & 8.1 \\
No malignancy & 12 & 32.4 \\
\hline Total & 37 & 100.0 \\
\hline
\end{tabular}

Comparison of findings of bronchial brush cytology and histopathology of endobronchial biopsy in 37 cases of bronchial carcinoma:
Findings of bronchial brush cytology and histopathology of endobronchial biopsy were shown in table 3 .

\section{Table-III}

Findings of bronchial brush cytology and histopathology of endobronchial biopsy in 37 cases of bronchial carcinoma $(n=37)$

\begin{tabular}{lcc}
$\begin{array}{l}\text { Cyto-histological } \\
\text { findings }\end{array}$ & $\begin{array}{c}\text { Brush } \\
\text { cytology }\end{array}$ & Histopathology \\
\hline Squamous cell carcinoma & $25(67.6)$ & $18(48.6)$ \\
Adenocarcinoma & $4(10.8)$ & $4(10.8)$ \\
Small cell carcinoma & $4(10.8)$ & $3(8.2)$ \\
Non-malignancy & $4(10.8)$ & $12(32.4)$ \\
\hline
\end{tabular}

Results of both endobronchial biopsy and bronchial brush cytology in 37 patients of central bronchial carcinoma were shown in Table 4. Final diagnosis of central lung lesion of bronchial carcinoma was squamous cell carcinoma in $28(75.7 \%)$ patients, small cell carcinoma in $5(13.5 \%)$ patients and adenocarcinoma in $4(10.8 \%)$ patients.

\section{Table-IV}

Findings of combined endobronchial biopsy and bronchial brush cytology in 37cases of bronchial carcinoma $(n=37)$

\begin{tabular}{lcc} 
Cyto-histopathology results & Frequency & Percentage \\
\hline Squamous cell carcinoma & 28 & 75.7 \\
Adenocarcinoma & 4 & 10.8 \\
Small cell carcinoma & 5 & 13.5 \\
\hline Total & 37 & 100.0 \\
\hline
\end{tabular}

Results of sensitivityendobronchial biopsy and bronchial brush cytology in the diagnosis of bronchial carcinoma were shown in Table 5. Sensitivity of bronchial brush cytology in the diagnosis of central lung lesion in bronchial carcinoma was $89.2 \%$; while the sensitivity of endobronchial biopsy in the diagnosis of central lung lesion in bronchial carcinoma was $67.6 \%$. There was no true negative case. There was a significant difference between sensitivity of bronchial brush cytology and endobronchial biopsy in the diagnosis of bronchial carcinoma $\left(C^{2}=5.103 ; \mathrm{p}=0.024\right)$. 
Table-V

\begin{tabular}{|c|c|c|c|}
\hline \multicolumn{4}{|c|}{$\begin{array}{l}\text { Sensitivity of endobronchial biopsy and bronchial brushing in the diagnosis } \\
\text { of central bronchial carcinoma }(n=37)\end{array}$} \\
\hline Method used & Diagnosis possible & Diagnosis not possible & p-value \\
\hline Bronchial brushing & $33(89.2)$ & $4(10.8)$ & $*_{\mathrm{p}}=0.024$ \\
\hline Endobronchial biopsy & $25(67.6)$ & $12(32.4)$ & \\
\hline
\end{tabular}

*Chi-Square $\left(\mathrm{C}^{2}\right)$ test was done to analyse the data. Figure in the parenthesis indicates corresponding percentage.

Comparison of sensitivity of endobronchial biopsy and bronchial brush cytology in the diagnosis of central bronchial carcinoma was shown in Table 4.13 . Sensitivity of bronchial brushing was significantly higher than that of endobronchial biopsy in the diagnosis of bronchial carcinoma $(Z=2.405 ; \mathrm{p}<0.05)$.

\section{Table-VI}

Comparison of sensitivity endobronchial

biopsy and bronchial brushing in the diagnosis of bronchial carcinoma $(n=37)$

\begin{tabular}{lccc} 
Diagnostic utility & $\begin{array}{c}\text { Bronchial } \\
\text { brushing }\end{array}$ & $\begin{array}{c}\text { Endobronchial } \\
\text { biopsy }\end{array}$ & $\mathrm{p}$-value \\
\hline Sensitivity & $89.2 \%$ & $67.6 \%$ & $* \mathrm{p}<0.05$ \\
\hline
\end{tabular}

$* \mathrm{Z}$ test for proportion was done to analyze the data.

\section{Discussion:}

The age of the patients with bronchial carcinoma ranged from 34 to 90 years with the mean age of $59.65 \pm 12.95$ years. This result was correlated with the study of Hassan et al. ${ }^{23}$ that age of the patients ranged from 35 to 85 years with the mean age of 60.14 years. This result was also in agreement with other studies. ${ }^{24,25.26}$ While Shah et al. ${ }^{27}$ reported the mean age of their patients with bronchial carcinoma was 45.6 years which was lower than the present study and Santos-Martínez et al. ${ }^{28}$ reported that the mean age was $67.1( \pm 11.1)$, which was higher than the present study.

In this study $35(94.6 \%)$ patients were male and 2 (5.4\%) patients were female with a ratio of male to female of 17.5:1. Male were more frequently affected by bronchial carcinoma than that of female $(p<0.001)$. Similar male preponderance of bronchial carcinoma were reported in several other studies. ${ }^{3,23,28,29}$ Male-Female ratio in this study is markedly increased which can be explained by some reasons like small sample size, less reporting of female patients in a tertiary care hospital and less common smoking habit in female in our country.

In this study the endobronchial biopsy and histopathology revealed bronchial carcinoma in 25 (67.6\%) patients and $12(32.4 \%)$ had no malignancy detected. Squamous cell carcinoma was diagnosed in $18(48.6 \%)$ patients, adenocarcinoma in $4(10.8 \%)$ patients and small cell carcinoma in $3(8.1 \%)$ patients. This result was consistent with the study of Santos-Martínezet al. ${ }^{28}$ that the most common histological types were squamous cell carcinoma (33.2\%) and adenocarcinoma (29.8\%). Small cell carcinoma was diagnosed in $13.1 \%$ and large cell carcinoma in $4.4 \%$ of patients. Choudhury et al. ${ }^{30}$ reported squamous cell carcinoma was the most common malignancy constituting $85.7 \%$ of cases, followed by small cell carcinoma $9.5 \%$ and adenocarcinoma in $4.7 \%$ of cases as confirmed by histological examination. In study by Rawatet al. ${ }^{31}$ found squamous cell carcinoma accounted in 51.4\%, adenocarcinoma in $11.2 \%$, large cell carcinoma in $3.7 \%$ ), unclassified in $15.9 \%$ and small cell carcinoma in $17.7 \%$ of cases.

In this study bronchial brush cytology revealed bronchial carcinoma in $33(89.2 \%)$ patients of which squamous cell carcinoma was in 25 (67.6\%), adenocarcinoma in $4(10.8 \%)$ and small cell carcinoma in $4(10.8 \%)$ patients. In this regards Agarwal etal. ${ }^{32}$ reported that bronchial brush cytology showed squamous cell carcinoma in $50.0 \%$, adenocarcinoma in $10.0 \%$ and large cell carcinoma in $40.0 \%$ of cases.

The diagnostic yield of bronchial carcinoma in endoscopically visible tumour by combined brush and biopsy was higher than individual techniques where all 37 cases were found having malignancy, squamous cell carcinoma was in $28(75.7 \%)$ patients, small cell carcinoma in $5(13.5 \%)$ and adenocarcinoma in $4(10.8 \%)$ patients. Shrestha et al. ${ }^{33}$ found squamous cell 
carcinoma $(60.9 \%)$ was the most common histological pattern of bronchial carcinoma, followed by small cell carcinoma (19.5\%) and adenocarcinoma (8.0\%). Tuladhar et al. ${ }^{16}$ found the various bronchogenic malignancies in decreasing order of frequency were squamous cell carcinoma (51\%), followed by small cell carcinoma (19\%), adenocarcinoma (11\%), non-small cell carcinoma (7\%), large cell carcinoma (4\%), carcinoma in situ (4\%) and small round cell tumor (4\%).

Sensitivity of bronchial brush cytology in the diagnosis of central lesion of bronchial carcinoma was $89.2 \%$; while the sensitivity of endobronchial biopsy in the diagnosis of central bronchial carcinoma was $67.6 \%$. Diagnostic sensitivity of bronchial brush cytology was significantly higher than that of endobronchial biopsy in the diagnosis of bronchial carcinoma. This result was concordant with the study of Alam, ${ }^{13}$ that showed bronchial brushings yielded a diagnosis of central bronchial carcinoma of $84 \%$ and that of bronchial biopsy it was $56.5 \%$. This result was also correlated with the study of Fuladi et al. ${ }^{34}$ that bronchial brushings yielded a diagnosis of bronchial carcinoma in $80.76 \%$ of visible lesions and that of bronchial biopsy was $76.9 \%$. Similar observation was found in the study of Qayyum, ${ }^{14}$ that bronchial brushings and bronchial biopsy yielded a diagnosis of central bronchial carcinoma of $88.4 \%$ and $60.0 \%$ respectively $(\mathrm{p}<0.001)$.

Similar observations were made by Gaur et al. ${ }^{35}$ who mentioned accuracy of brushing was $93.90 \%$. Choudhury et al. ${ }^{30}$ reported that sensitivity of bronchial brushings in the diagnosis of bronchial carcinoma was $82.8 \%$. But the diagnostic yield of brushings in patients with endoscopically visible (central) tumors varies from 52 to $77 \%$ which were inferior to that of biopsies $(71 \%$ to $91 \%$ ) reported in some other studies. ${ }^{36,37}$

The superiority of bronchial brushing over bronchial biopsy in central (visible) tumours was seen paradoxical; however, there were several reasons which we believed explain this observation. The most important is that the brush was stroked to and fro over a considerable (1 to 2 $\mathrm{cm}$ ) surface of the tumour, increasing the likelihood of obtaining some cells with malignant characteristics on the bristles of the brush. On the other hand the biopsy forceps has a cup diameter only slightly greater than 1 $\mathrm{mm}$; the specimens obtained with the biopsy forceps are small and come from only one area of tumour which might not be representative sample. Furthermore in this study the bronchial brushing was performed before endobronchial biopsy, thus bleeding resulting from brushing may obscure the site of lesion during endobronchial biopsy which might be a cause of more negative results in endobronchial biopsy. Moreover, endobronchial biopsy was not satisfactory in four cases in which FNAC results under radiological guidance were taken as equivalent to endobronchial biopsy.

\section{Conclusions:}

This study revealed that the bronchial brush cytology was minimally invasive, well tolerated procedure with high sensitivity in diagnosis of central lesion of bronchial carcinoma. The sensitivity of bronchial brush cytology was $89.2 \%$ and that of endobronchial biopsy was $67.6 \%$ in the diagnosis of central bronchial carcinoma.

So, it is concluded that the diagnostic yield of bronchial brush cytology is higher than that of endobronchial biopsy in central (endoscopically visible) bronchial carcinoma.

\section{References:}

1. Reid PT, Innes JA. Respiratory disease. In: Walker BR, Colledge NR, Ralston SH, Penman ID, editors. Davidson's Principles and Practice of Medicine. $22^{\text {nd }}$ ed. Edinburgh: Elsevier, Churchill Livingstone; 2014. pp. 643-732.

2. Behera D. Lung Cancer in India. Medicine Update. 2012; 22: 401-7

3. Akhtar PS, Masud ZM, Alam MT, Begum M. Profile of Lung Cancer: A One-Year Report. J Medicine. 2011;12:115-9.

4. Spitz MR, Wei Q, Dong Q, Amos CI, Wu X. Genetic susceptibility to lung cancer: The role of DNA damage and repair. Cancer Epidemiol Biomarkers Prev. 2003;12:689-98.

5. Young JA. Techniques in pulmonary cytopathology. ACP broadsgheet 140. J ClinPathol. 1993; 46: 589-95.

6. Ahmad M, Afzal S, Saeed W, Mubarik A, Saleem N, Khan SA, et al. Efficacy of Bronchial Wash Cytology and its correlation with Biopsy in Lung Tumours. J Pak Med Assoc. 2004; 54(1): 13-6.

7. Postmus PE. Bronchoscopy for lung cancer. Chest 2005; 128: $16-8$.

8. Lee HS, Kwon SY, Kim DK, Yoon Hi, Lee S-M, Lee JH, et al. Bronchial washing yield before and after forceps biopsy in patients with endoscopically visible lung cancers. Respirology 2007; 12: 277-82. 
9. Dobler CC, Crawford ABH. Bronchoscopic diagnosis of endoscopically visible lung malignancies: should cytological examinations be carried out routinely? Int Med J. 2009;39: 806-11.

10. Popp W, Merkle M, Schreiber B, Rauscher H, Ritschka L, Zwick H. How much brushing is enough for the diagnosis of lung tumors? Cancer. 1992; 70: 2278-80.

11. Popp W, Rauscher H, Ritschka L, Redtenbacher S, Zwick H, Dutz W. Diagnostic sensitivity of different techniques in the diagnosis of lung tumors with the ûexible ûberoptic bronchoscope. Comparison of brush biopsy, imprint cytology of forceps biopsy, and histology of forceps biopsy. Cancer. 1991; 67: 72-5.

12. Firoozbakhsh S, Safavi E. Bronchoalveolar Lavage in the Assessment of Peripheral Lung Cancer. Tanaffos. 2003; 2(7): 7-10.

13. Alam MR. Role of brushing, biopsy and broncho-alveolar lavage (BAL) in the diagnosis of mitotic lesion of lungs (MD Thesis). University of Dhaka. 2002.

14. Qayyum MA. Role of bronchial brushing and bronchial biopsy in the diagnosis of lung cancer(MD thesis).University of Dhaka. 2000.

15. Garg S, Handa U, Mohan H, Janmeja AK. Comparative analysis of cytohistological techniques in diagnosis of lung diseases. DiagnCytopathol. 2007;35:26-31.

16. Tuladhar A, Panth R, Joshi AR. Comparative analyses of cytohistologic techniques in diagnoses of lung lesions. Journal of Pathology of Nepal. 2011; 1: 126 -30.

17. Jones AM, Hanson IM, Armstrong GR, O'Driscoll BR. Value and accuracy of cytology in addition to histology in the diagnosis of lung cancer at flexible bronchoscopy. Respir Med. 2001;95:374-8.

18. Govert JA, Kopita JM, Matchar D, Kussin PS, Samuelson WM. Cost effectiveness of collecting routine cytologic specimens during fiberoptic bronchoscopy for endoscopically visible lung tumor. Chest. 1996;109: 451-6.

19. Mak VHF, Johnston IDA, Hetzel MR, Grubb C. Value of washings and brushings at fiberoptic bronchoscopy in the diagnosis of lung cancer. Thorax. 1990;45:373-6.

20. Lam B, Wong MP, Ooi C, Lam WK, Chan KN, Ho JC, et al. Diagnostic yield of bronchoscopic sampling methods in bronchial carcinoma. Respirology 2000; 5: 265-270

21. Khan RSA, Uddin R. Malignant Lung Tumours; Efficacy of bronchial wash cytology and its correlation with biopsy in diagnosis. Professional Med J. 2009; 16(2):187-91.

22. Behera $D$, Balamugesh $T$. Lung Cancer in India. Indian $J$ Chest Dis Allied Sci. 2004; 46: 269-81.

23. Hassan MQ, Ahmead MSU, Rahman MZ, Ahmed S, Chowdhury MAW. Clinico-pathological profile of bronchogenic carcinoma in a tertiary care hospital in Bangladesh. JCMCT. 2010; 21(1):45-9.
24. Gaur DS, Kusum A, Harsh M, Kohli S, Kishore S, Pathak VP. Efficacy of Bronchial Brushings and Trans-Bronchial Needle Aspiration in Diagnosing Carcinoma Lung. J Cytol. 2007; 24 (1): 46-50

25. Bodh A, Kaushal V, Kashyap S, Gulati A. Cytohistological correlation in diagnosis of lung tumors by using fiberoptic bronchoscopy: Study of 200 cases. Indian J PatholMicrobiol. 2013;56:84-8.

26. Guimarães MD, Chojniak R, Gross JL, Bitencourt AGV. Predictive success factors for CT-guided fine needle aspiration biopsy of pulmonary lesions. Clinics. 2009; 64 (12): 1139-44

27. Shah RH, Inayat N, Maitlo HB, Khitchi GJ. Ultrasound guided transthoracic biopsy in peripheral lung $\&$ mediasteneal masses with trucut needle. Medical Channel. 2010; 16 (1): 136-9.

28. Santos-Martínez MJ, Curull V, Blanco ML, Macià F, Mojal $\mathrm{S}$, Vila J, et al. Lung Cancer at a University Hospital: Epidemiological and Histological Characteristics of a Recent and a Historical Series. Arch Bronconeumol. 2005;41(6):307-12.

29. Tatar D, Gunes E, Erbaycu AE, Yucel N, Halilcolar H. The Contribution of Bronchoalveolar Lavage Performed Before and After Bronchoscopic Biopsies to the Diagnosis of Peripheral Lung Cancer. UHOD. 2011; 2(2): 80-6.

30. Choudhury M, Singh S, Agarwal S. Efficacy of Bronchial Brush Cytology and Bronchial washings in Diagnosis of non-neoplastic and neoplastic Bronchopulmonary lesions. Turk PatolojiDerg. 2012, 28:142-6.

31. Rawat J, Sindhwani G, Saini S, Kishore S, Kusum A, Sharma A. Usefulness and cost effectiveness of bronchial washing in diagnosing endobronchial malignancies. Lung India. 2007; 24:139-41.

32. Agarwal A, Ghotekar LH, Garbyal RS, Mital VP, Chokhani R. Evaluation of Pulmonary Malignancies in Khatmandu Valley and Role of Bronchoschopic Techniques in Diagnosis of Such Cases.JICAM.2003; 4(2): 127-33.

33. Shrestha HG, Chokhani R, Dhakhwa R. Clinicopathological profile of Bronchogenic carcinoma. J Nepal Med Assoc. 2010; 49 (178): 100-3.

34. Fuladi AB, Munje RP, Tayade BO. Value of Washings, Brushings, and Biopsy at Fibreoptic Bronchoscopy in the Diagnosis of Lung Cancer. JIACM. 2004; 5(2): 137-42.

35. Gaur DS, Thapiyal NC, Kishore S, Pathak VP. Efficacy of bronchial alveolar lavage and bronchial brush cytology in diagnosing lung cancers. J Cytol. 2007; 24:73-7.

36. Kvale PA, Bode FR, Kini S. Diagnostic accuracy in lung cancer; comparison of techniques used in association with ûexible ûberoptic bronchoscopy. Chest. 1976; 69:752-7.

37. Saltzstein, SL, Harrell JH, Cameron T. Brusings, washings, or biopsy? Obtaining maximum value from flexible fiberoptic bronchoscopy in the diagnosis of cancer. Chest.1977; 71 (5): 630- 2. 